\title{
NOTES ON LEAF AND STEM ANATOMY OF Thlaspi sensu lato
}

\author{
Mehmet Cengiz KARAİSMAIILOĞLU ${ }^{1 *}$, Osman EROL ${ }^{2}$ \\ ${ }^{1}$ Department of Biology, Faculty of Arts and Sciences, Siirt University, Siirt, TURKEY \\ ${ }^{2}$ Division of Botany, Department of Biology, Faculty of Science, İstanbul University, İstanbul, TURKEY
}

Cite this article as:

Karaismailoğlu M.C., Erol O. 2020. Notes on Leaf and Stem Anatomy of Thlaspi sensu lato. Trakya Univ J Nat Sci, 21(2): 139-150, DOI: 10.23902/trkjnat.762509

Received: 01 July 2020, 16 September 2020, Online First: 02 October 2020, Published: 15 October 2020

Edited by:

Mykyta Peregrym

*Corresponding Author:

Mehmet Cengiz Karaismailoğlu

cengiz.karaismailoglu@siirt.edu.tr

\section{ORCID ID:}

orcid.org/0000-0002-6856-2742

Key words:

Anatomy

$P C A$

Stomatal index

UPGMA

\begin{abstract}
In this study, anatomical characteristics of leaves and stems of 19 taxa of Thlaspi sensu lato, 9 of which are endemic to Turkey, were investigated in order to determine taxonomic relationships among the studied taxa. The anatomical characteristics of all taxa were determined and assessed using the cluster analysis and the principal component analysis. The transverse sections of the leaves and stems exhibited various diagnostic characters in terms of the pattern of epidermal cell and mesophyll layers, the number and size of vascular bundles, and the thickness of the cortex and endodermis. Important differences were detected in number, size, and index of stomata, and in epidermal cell wall structures in the adaxial and abaxial surfaces. The results showed that the compared anatomical characteristics among taxa are partially compatible with their sectional delimitation in their traditional rank in The Flora of Turkey and the East Aegean Islands. The results also point out that some taxonomic re-arrangements may be required.
\end{abstract}

Özet: Bu çalışmada, 9'u Türkiye için endemik olan 19 Thlaspi sensu lato taksonunun yaprak ve gövde anatomik karakterleri, taksonlar arasındaki taksonomik ilişkileri belirleme amacıyla tanımlanmıștır. Tüm taksonların anatomik karakterleri belirlendi ve kümeleme analizi ve temel bileşen analizi kullanılarak değerlendirildi. Yaprakların ve gövdelerin enine kesitleri epidermal hücre ve mezofil tabakalarının yapıları, vasküler demetlerin sayısı ve boyutu, korteks ve endodermisin kalınlığı açısından çeşitli teşhis karakterleri gösterdi. Ayrıca, adaksiyal ve abaksiyal yüzeylerde stomaların sayı, boyut ve indeksinde ve epidermal hücre duvarı yapılarında önemli farklılıklar saptandı. Bu sonuçlar taksonlar arasındaki karşılaştırılmış anatomik özelliklerin Türkiye Florası ve Doğu Ege Adaları'ndaki geleneksel sıralamasındaki seksiyon sınırlamaları ile kısmen uyumlu olduğunu göstermektedir. Elde edilen veriler ayrıca bazı taksonomik yeniden düzenlemelerin gerekli olabileceğine işaret etmektedir.

\section{Introduction}

Brassicaceae is a large and important plant family in terms of economically significant species and model organisms such as Arabidopsis Heynh. and Brassica L. The family has approximately 338 genera and 3709 species worldwide, primarily in temperate zones of the Northern Hemisphere (Al-Shehbaz et al. 2006). In Turkey, Brassicaceae includes 571 species with 65 subspecies, 24 varieties and 660 taxa belonging to 91 genera (Al-Shehbaz et al. 2007). Thlaspi L. is known to be one of the largest genera of Brassicaceae and it has 75 species distributed mainly in Eurasia (Al-Shehbaz 1986, Appel \& Al-Shehbaz 2003). The genus, represented by 36 taxa at various levels, is diverse in Turkey. Twenty-one of these taxa are endemic to Turkey, making the endemism rate of the genus 58\% (Davis 1988, Karaismailoğlu \& Erol 2019).

The classification in generic and subgeneric categories of Thlaspi sensu lato is quite confused with complex taxonomy and nomenclature. The traditional understanding of Thlaspi was radically changed with Meyer's works
(1973, 1979, 1991, 2001), which were based on seed coat anatomy. Meyer divided the genus into 12 genera and maintained only six taxa in Thlaspi (Thlaspi sensu stricto). Many researchers (Greuter \& Raus 1983, Greuter et al. 1986, Al-Shehbaz 1986, Artelari 2002, Appel \& AlShehbaz 2003, Al-Shehbaz 2014, Karaismailoğlu \& Erol 2018) opposed this classification by considering it as not practical for taxonomy and its extensive-scale use extremely limited (Al-Shehbaz 2014). In the following years, remarkable molecular phylogenetic studies such as Mummenhoff \& Koch (1994), Zunk et al. (1996), Mummenhoff et al. (1997a, 1997b), Koch et al. (1998), Koch et al. (2001) clearly showed that the classification of Meyer (1973, 1979) was baseless (Al-Shehbaz 2014). However, despite the numerous works on the infrageneric and interspecific taxonomy of the genus, problems have yet to be elucidated.

Metcalfe \& Chalk (1957) showed that the important distinctive anatomical characters of Brassicaceae include 
epidermal cell type, stoma type and structures of the vascular bundles, which may provide insight into many taxonomical characters demonstrated to be significant in the species classification (Stace 1984). Many such data on these characters have been extensively used in taxonomical assignments (Liu \& Zhu 2011, Selvi \& Paksoy 2013, Ozcan et al. 2015, Karaismailoğlu 2016, 2019).

There is a lack of data in literature on anatomical features of Thlaspi taxa except those of seed anatomy (Karaismailoğlu \& Erol 2019). This paper offers the first comprehensive assessment of the systematic importance of leaf and stem anatomy in the examined Thlaspi taxa.

\section{Materials and Methods}

\section{$\underline{\text { Samples }}$}

The examined taxa were collected from various phytogeographic regions of Turkey (Table 1). Voucher specimens are deposited in the Istanbul University Science Faculty Herbarium (ISTF).

\section{Anatomical preparations}

Anatomical studies were made using specimens preserved in $70 \%$ alcohol. Cross sections were taken with a fully automatic microtome (Thermo Shonda Met Finesse) from the stem and cauline leaves. Subsequently, they were taken through alcohol and xylene series, stained with hematoxylin (Harris-RRSP67-E) in a staining device (ASC 720 Medite) and covered with Entellan for examination of the anatomical structures (Karaismailoğlu 2015a, 2015b, Karaismailoğlu \& Güner 2019). The stomatal density of leaf surfaces was enumerated using surface sections taken by hand. Anatomical characters were observed using an Olympus CX21FS1 microscope and Kameram Imaging Software.

The terminology used for anatomical characters of the leaves follows Wilkinson (1979) and Stace (1984).

Table 1. The locality and collection data details of the examined taxa.

\begin{tabular}{|c|c|c|c|}
\hline Section & Taxa & Locality & $\begin{array}{c}\text { Collection } \\
\text { number }\end{array}$ \\
\hline \multirow{2}{*}{ Nomisma DC. } & T. arvense L. (T1) & $\begin{array}{l}\text { Samsun, Kavak-Akdağ, agricultural field edges, } 766 \text { m, } \\
\text { 2.5.2015 }\end{array}$ & Karaismailoğlu 139 \\
\hline & T. huetii Boiss. (T2) & $\begin{array}{l}\text { Artvin, Şavşat, Ciritdüzü village, roadside, stony areas, } \\
2050 \text { m, 10.07.2014 }\end{array}$ & Karaismailoğlu 66 \\
\hline \multirow{6}{*}{ Thlaspi L. } & T. orbiculatum Stev. (T3) & $\begin{array}{l}\text { Artvin, Ardanuç, above Peynirli village, steep slopes, } \\
1663 \text { m, 15.06.2015 }\end{array}$ & Karaismailoğlu 201 \\
\hline & T. kotschyanum Boiss. \& Hohen. (T4) & $\begin{array}{l}\text { Kahramanmaraş, Göksun, Berit Mountain, humid areas, } \\
2116 \text { m, 19.06.2015 }\end{array}$ & Karaismailoğlu 202 \\
\hline & T. perfoliatum L. (T5) & $\begin{array}{l}\text { Tekirdağ, Tekirdağ-Kırklareli, roadsides and inclined } \\
\text { slopes, } 273 \mathrm{~m}, 21.03 .2015\end{array}$ & Karaismailoğlu 109 \\
\hline & T. annuum Koch (T6) & $\begin{array}{l}\text { Amasya, Boraboy, village-lake, inclined slopes, } 881 \mathrm{~m} \text {, } \\
\text { 02.05.2015 }\end{array}$ & Karaismailoğlu 143 \\
\hline & T. bulbosum Spruner ex Boiss. (T7) & $\begin{array}{l}\text { Kahramanmaraş, Andırın, Meryemçil plateau, grassland, } \\
1633 \text { m, 21.06.2015 }\end{array}$ & Karaismailoğlu 209 \\
\hline & T. leblebicii Gemici \& Görk (T8)* & $\begin{array}{l}\text { Muğla, Köyceğiz, Sandras Mountain, Ağla village, } \\
\text { roadsides, stony slopes, } 1262 \mathrm{~m}, 05.06 .2015\end{array}$ & Karaismailoğlu 192 \\
\hline \multirow{11}{*}{ Pterotropis DC. } & T. ochroleucum Boiss. (T9) & $\begin{array}{l}\text { Hatay, Dörtyol, Topaktaş-Karamezra plateau, Fagus } \\
\text { forest, stony slopes, } 1752 \mathrm{~m}, 24.04 .2016\end{array}$ & Karaismailoğlu 240 \\
\hline & T. violascens Schott \& Kotschy (T10)* & $\begin{array}{l}\text { Osmaniye, Düziçi, Dumanlı Mountain, forest, } 1259 \text { m, } \\
\text { 26.05.2015 }\end{array}$ & Karaismailoğlu 181 \\
\hline & T. densiflorum Boiss. \& Kotschy (T11)* & $\begin{array}{l}\text { Kahramanmaraş, Ahir Mountain, Ulucak hill, stony } \\
\text { slopes, } 1751 \mathrm{~m}, 20.06 .2015\end{array}$ & Karaismailoğlu 205 \\
\hline & T. cataonicum Reuter (T12)* & $\begin{array}{l}\text { Adana, Saimbeyli, Obruk plateau, grassland, } 1472 \mathrm{~m} \text {, } \\
\text { 18.04.2015 }\end{array}$ & Karaismailoğlu 124 \\
\hline & T. elegans Boiss. (T13)* & $\begin{array}{l}\text { Osmaniye, Düziçi, near Haruniye, open fields and } \\
\text { inclined slopes, roadside, } 797 \text { m, 19.04.2015 }\end{array}$ & Karaismailoğlu 130 \\
\hline & T. rosulare Boiss. \& Balansa (T14)* & $\begin{array}{l}\text { Niğde, Çamard, Yelatan village, stony slopes, } 2085 \mathrm{~m} \text {, } \\
\text { 25.05.2015 }\end{array}$ & Karaismailoğlu 173 \\
\hline & T. praecox Wulfen subsp. praecox (T15) & $\begin{array}{l}\text { Kırklareli, Dereköy, roadsides, stony areas, } 520 \text { m, } \\
\text { 09.06.2015 }\end{array}$ & Karaismailoğlu 197 \\
\hline & T. cariense A. Carlström (T16)* & $\begin{array}{l}\text { Muğla, Marmaris, Kırzeytin Mountain, serpentine rocks, } \\
494 \mathrm{~m}, 05.06 .2015\end{array}$ & Karaismailoğlu 190 \\
\hline & T. tatianae Bordz. (T17) & $\begin{array}{l}\text { Van, Güzeldere-Başkale, Güzeldere pass, summit, } \\
\text { wetlands, } 2651 \mathrm{~m}, 30.05 .2015\end{array}$ & Karaismailoğlu 186 \\
\hline & T. aghricum P.H. Davis \& Kit Tan (T18)* & $\begin{array}{l}\text { Ağrn, Hamur-Tutak, meadow, inclined slopes, } 1605 \text { m, } \\
\text { 16.05.2015 }\end{array}$ & Karaismailoğlu 162 \\
\hline & T. watsonii P.H. Davis (T19)* & $\begin{array}{l}\text { Van, Güzeldere-Başkale, Güzeldere pass, summit, } 2752 \\
\text { m, 02.07.2015 }\end{array}$ & Karaismailoğlu 210 \\
\hline
\end{tabular}




\section{$\underline{\text { Statistical analysis }}$}

The data obtained from the examined parameters were evaluated with the SPSS (Statistical Package for the Social Sciences) and MVSP (Multi Variate Statistical Package) computer programs. The Duncan multiple-range test of the SPSS was used to determine the statistical importance of differences among the quantitative values obtained for different taxa in Tables 2-4 (SPSS 2006). Grouping of taxa was carried out utilizing the clustering analysis method (UPGMA) of the MVSP in accordance with the 36 characters in Tables 2-4 (Fig. 5). Principal component analysis (PCA) ordination of the MVSP was also performed (Fig. 6 and Table 5) (Kovach 2007).

\section{Results}

The comparative anatomical characteristics of the leaves and the stems are presented in Tables 2-4 and Figs $1-4$, demonstrating important differences among the taxa. Tables 2-3 and Figs 1-3 show the anatomical features of the leaves and Table 4 and Fig. 4 show the anatomical characters of the stems of the examined taxa.

The cross-sections of the leaves feature a thin cuticle, which is more prominent in T4 and T6 than in other taxa, on the adaxial and abaxial epidermis. Epidermal cells are isodiametric and mostly range from square to rectangular in shapes, rarely polygonal. The thickness of the adaxial epidermis layer varies between 28.12 X $7.19 \mu \mathrm{m}$ (T3) and $3.21 \mathrm{X} 5.16 \mu \mathrm{m}$ (T11), while the abaxial epidermis layer ranges from 69.77 X $6.14 \mu \mathrm{m}$ (T4) to 4.08 X $2.98 \mu \mathrm{m}$ (T1) (Table 2 and Fig. 1). The adaxial epidermis cells in most taxa are thicker than abaxial epidermis cells.

Most of the examined taxa have unifacial-type or twolayered, rarely three-layered (equifacial in T2 and T9) mesophyll with an arrangement of 2-4 layers of palisade parenchyma and 3-5 layers of spongy parenchyma with small intercellular gaps (Fig. 1). Mesophyll thickness ranges from 65.22 to $152.31 \mu \mathrm{m}$. It is widest in T17 and narrowest in T16 (Table 2). Most of the taxa appear to have straight anticlinal cell walls in epidermal layers, but T4, T7, T13, T17 and T19 have sinuous cell walls. The anticlinal cell walls of most of the taxa are sinuous on the abaxial surface, excluding T4, T15 and T16, which shows straight anticlinal cell walls.

Midrib dimensions varies from 50.12 (T7) to 95.91 $\mu \mathrm{m}$ (T8) in length, from 45.18 (T11) to $102.41 \mu \mathrm{m}$ (T16) in width (Table 2). Midrib sizes are generally bigger in the taxa of the Pterotropis section than in the Nomisma and Thlaspi sections. The midribs are usually oval in shape; however, this varied, being circular to elliptical with a convex abaxial midrib surface in T10, T12, T16 and T18. Collateral vascular bundles are organized in a single row and enclosed with parenchymatic sheath cells.

Three different types of epidermal cells were observed on the leaf surfaces: irregular, polygonal, and rectangular (Figs 2-3). The stomatal index is between 12.37 (T3) and 63.01 (T5) on the adaxial surface, and 10.18 (T7) and 51.55 (T5) on the abaxial surface (Table 3). The stomata type of researched taxa were defined as anisocytic, and rarely anomocytic, which appeared to be on the same level as the epidermis. Stoma size differed substantially among the examined Thlaspi taxa. The largest stomatal size was found on the adaxial and abaxial surfaces of T18 and T17, whilst the smallest ones were observed on the adaxial and abaxial surfaces of T3 (Table 3, Figs 2-3)

The one-layer epidermis consisting of flat, square, or rectangular cells, with a thin cuticle $(0.4-2 \mu \mathrm{m})$ on the outside was observed in stem cross sections. The surface is hairless, but there are protrusions in $\mathrm{T} 1$ and $\mathrm{T} 2$ (in the Nomisma section only) (Table 4 and Fig. 4). The epidermis layer is amphistomatic. The cortex consists of 3-12 parenchyma layers with thin- or thick-walled, regularly flat, or circular cells. Its thickness ranges from 14.46 (in T3) to 116.85 (in T11) $\mu \mathrm{m}$ (Table 4). Starch granules were observed in the cortex parenchyma. The endodermis layer located under the cortex consists of 1 or rarely 2 seriate flat-shaped cells, varying between $8.07 \mu \mathrm{m}$ (T19) and $28.75 \mu \mathrm{m}$ (T7) in length and between 3.84 (T10) and $12.87 \mu \mathrm{m}$ (T11) in width. The number of bundles ranges from 5-6 (T5 and T7) to 14-16 (T4) (Table 4 and Fig. 4). This number is notably larger in taxa of the Pterotropis section compared to Nomisma and Thlaspi. The dimensions of the vascular bundles are 70.53-130.84 $\mu \mathrm{m}$ in length, and 40.62-156.06 $\mu \mathrm{m}$ in width (Table 4). The interfascicular region was found between vascular bundles in some of the examined taxa. Generally, cambium cells were not obvious. Some of the examined taxa also have a layer of scleranchymatic cells between 31.14 and $102.45 \mu \mathrm{m}$ thick. The pith consists of polygonal or circular parenchymatic cells.

The unweighted pair group method with arithmetic mean (UPGMA) dissimilarity clustering dendrogram for 36 anatomical characters of leaves and stems of 19 Thlaspi taxa is presented in Fig. 5, and their infraspecific correlations in Tables (2-4). The dendrogram distinguishes the two major clusters and subsets from all other examined species. T11, T17, T14, T8, T13 and T7 form the first main cluster at a distance coefficient of about 25.0, while 13 other taxa make up the second main cluster at a distance coefficient of about 22.0. As indicated in the dendrogram, T11, T16, T5, T9 and T19 are markedly different from other taxa based on the examined characteristics (Tables 24). The clades included closely correlated taxa such as T3T4, T1-T2 and T9-T19, consistent with the traditional taxonomic rank of Thlaspi taxa in Turkey.

The principal component analysis (PCA) ordination and dissimilarity matrix according to the anatomical characteristics of leaves and stems are given in Table 5 and Fig. 6. The closest and most distant taxa are defined. T9 and T19 are the most closely related taxa (dissimilarity percentage: 9.46), whereas T9 and T11 are the most distant taxa (dissimilarity percentage: 32.00 ) (Table 5 and Fig. 5). Additionally, the cumulative variance value of principal components reached $68.27 \%$ (Axis 1: $47.55 \%$, Axis 2: 20.72\%). 
1

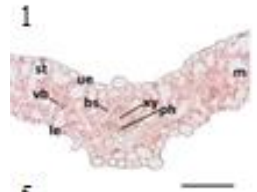

5

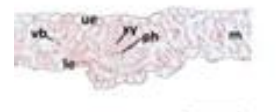

9

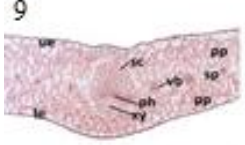

13

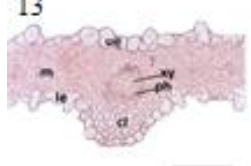

17

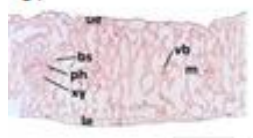

2

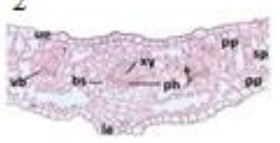

6

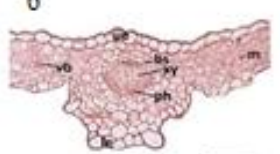

10

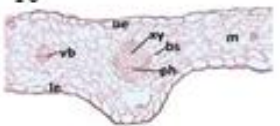

14

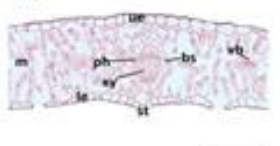

18

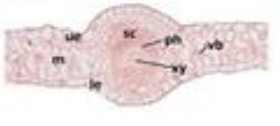

3
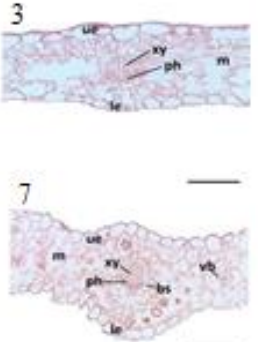

11

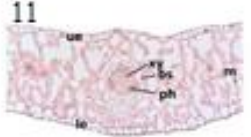

15

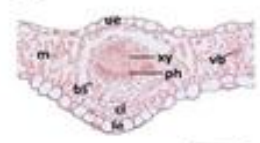

19

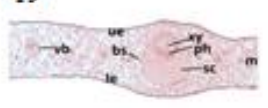

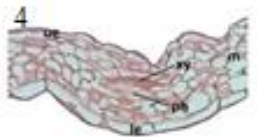
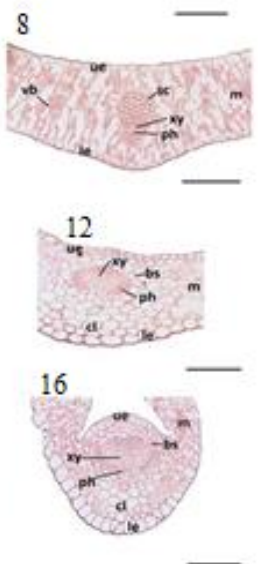

Fig. 1. Leaf cross sections of 1: T. arvense, 2: T. huetii, 3: T. orbiculatum, 4: T. kotschyanum, 5: T. perfoliatum, 6: T. annuum, 7: $T$. bulbosum, 8: T. leblebicii, 9: T. ochroleucum, 10: T. violascens, 11: T. densiflorum, 12: T. cataonicum, 13: T. elegans, 14: T. rosulare, 15: T. praecox subsp. praecox, 16: $T$. cariense, 17: T. tatianae, 18: $T$. aghricum, 19: T. watsonii. (ue: upper epidermis, le: abaxial epidermis: vb: vascular bundle, bs: bundle sheath, ph: phloem, xy: xylem, st: stoma, sc: sclerenchymatic cells, m: mesophyll, cl: collenchyma, scale bars: $100 \mu \mathrm{m}$.)
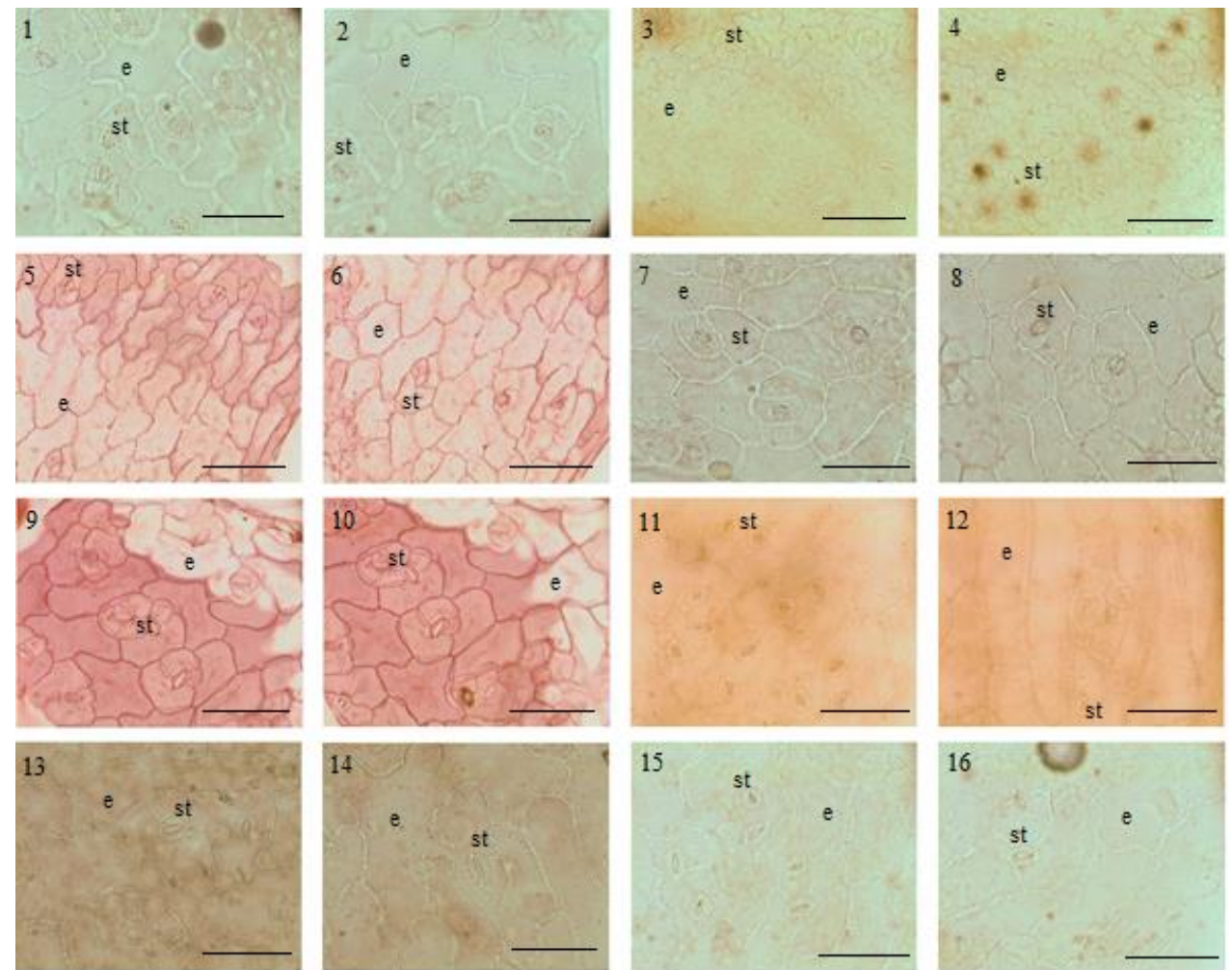

Fig. 2. Leaf surface patterns of 1-2: T. arvense, 3-4: T. huetii, 5-6: T. orbiculatum, 7-8: T. kotschyanum, 9-10: T. perfoliatum, 11-12: T. annuum, 13-14: . bulbosum, 15-16: T. leblebicii (e: epidermis, st: stoma, scale bars: $100 \mu \mathrm{m}$, odd numbers show adaxial surfaces, even numbers show abaxial surfaces). 

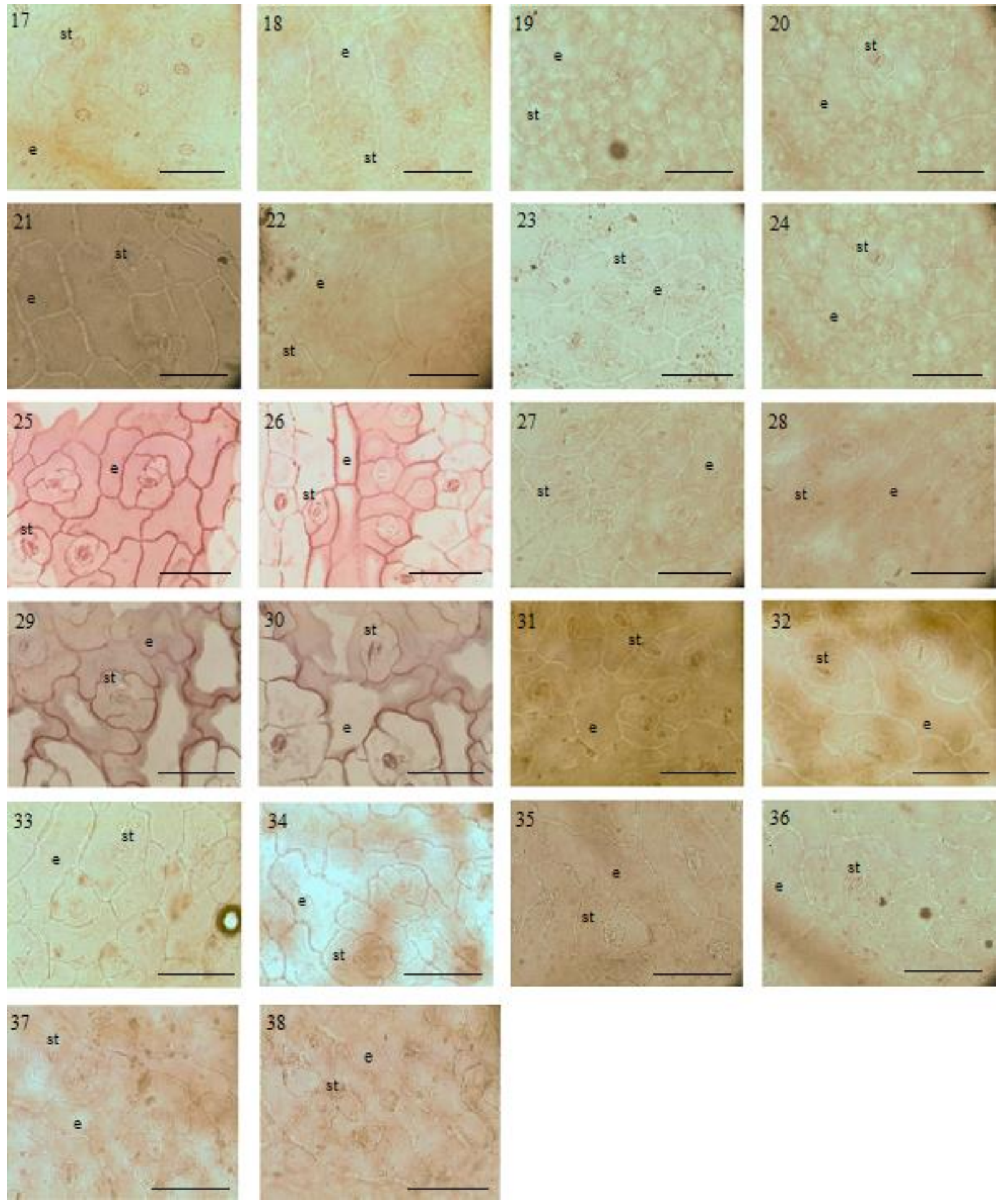

Fig. 3. Leaf surface patterns of 17-18: $T$. ochroleucum, 19-20: $T$. violascens, 21-22: $T$. densiflorum, 23-24: $T$. cataonicum, 25-26: $T$. elegans, 27-28: $T$. rosulare, 29-30: T. praecox subsp. praecox, 31-32: T. Cariense, 33-34: T. tatianae, 35-36: . aghricum, 37-38: $T$. watsonii (e: epidermis, st: stoma, scale bars: $100 \mu \mathrm{m}$, odd numbers show adaxial surfaces, even numbers show abaxial surfaces). 

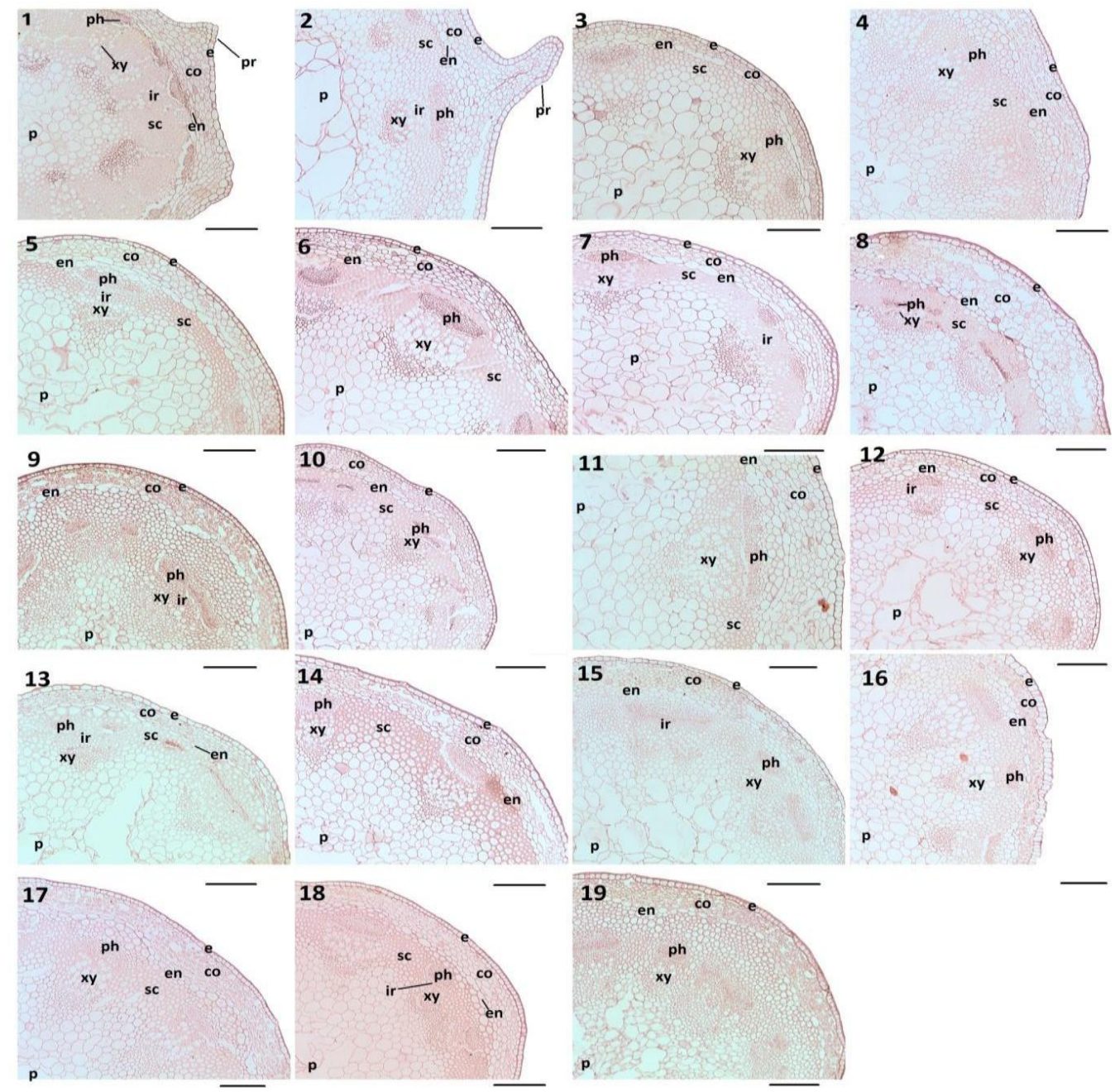

Fig. 4. Stem anatomical patterns of 1: T. arvense, 2: T. huetii, 3: T. orbiculatum, 4: T. kotschyanum, 5: T. perfoliatum, 6: T. annuum, 7: T. bulbosum, 8: T. leblebicii, 9: T. ochroleucum, 10: T. violascens, 11: T. densiflorum, 12: T. cataonicum, 13: T. elegans, 14: T. rosulare, 15: $T$. praecox subsp. praecox, 16: $T$. cariense, 17: $T$. tatianae, 18: T. aghricum, 19: $T$. watsonii. (e: epidermis, co: cortex, en: endodermis, ph: phloem, xy: xylem, ir: interfascicular region, sc: sclerenchymatic region, p: pith, scale bars: $100 \mu \mathrm{m}$.)

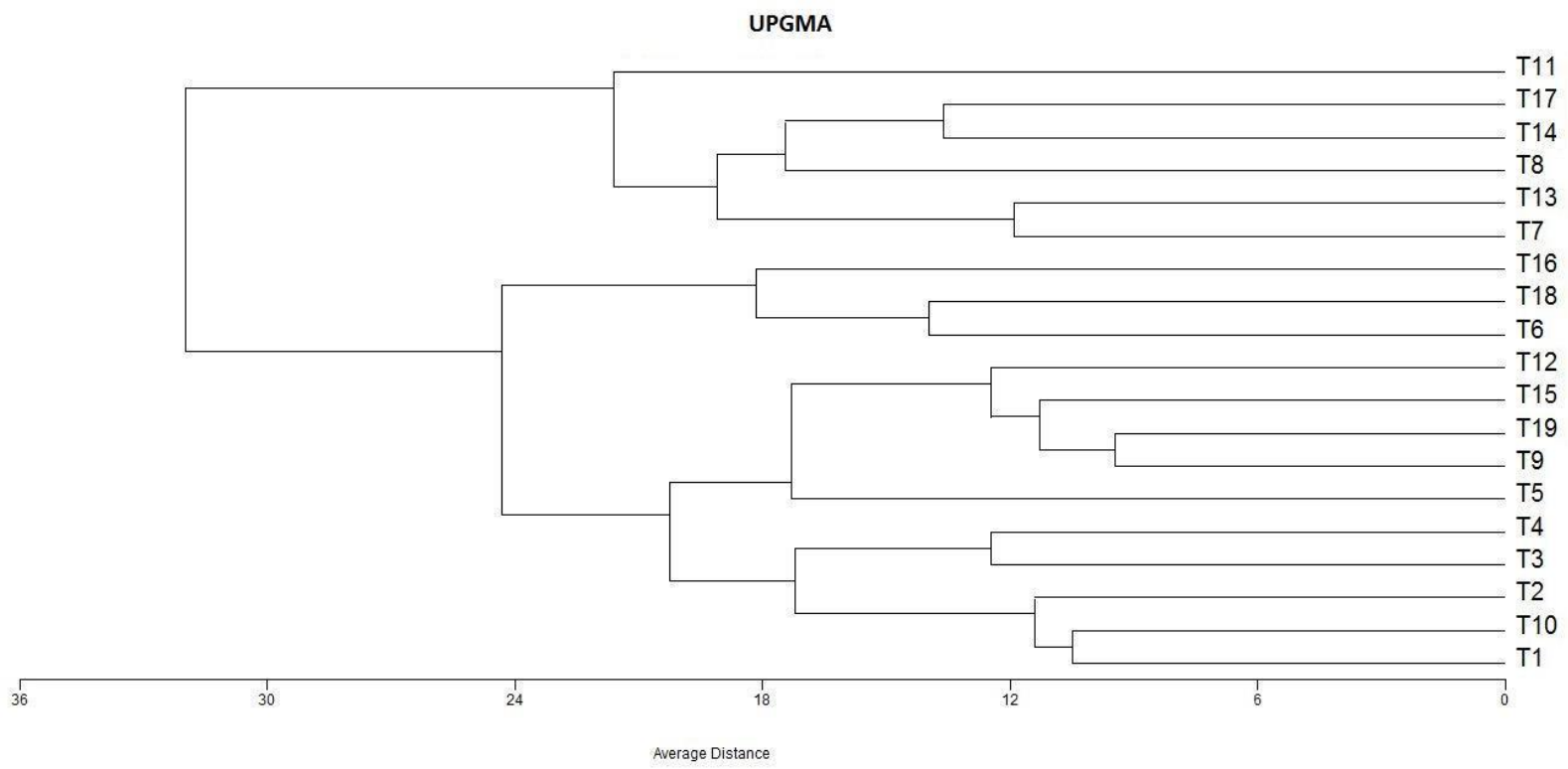

Fig. 5. The dendrogram obtained with UPGMA of the examined taxa (See Table 1 for taxa abbreviations). 
Table 2. Anatomical characteristics of leaves of the examined taxa. Outcomes represent mean values \pm standard deviation; means with different letters are significant at $\mathrm{p}=0.05$ level (Duncan's multiple-range test), for taxa abbreviations see Table 1 (L: Length, W: Width).

\begin{tabular}{|c|c|c|c|c|c|c|c|c|c|}
\hline \multirow{4}{*}{ Taxa } & \multicolumn{8}{|c|}{ Leaf } & \multirow{4}{*}{$\begin{array}{l}\text { Abaxial Epidermis } \\
\text { L (11) X W (12) }\end{array}$} \\
\hline & \multirow{2}{*}{$\begin{array}{l}\text { Adaxial Epidermis } \\
\text { L (1) X W (2) }\end{array}$} & \multicolumn{3}{|c|}{ Midrib } & \multirow{3}{*}{$\begin{array}{c}\text { Xylem } \\
\text { Height } \\
(7) \\
(\mu \mathrm{m})\end{array}$} & \multirow{3}{*}{$\begin{array}{c}\text { Phloem } \\
\text { Height } \\
(8) \\
(\mu \mathrm{m})\end{array}$} & \multirow{3}{*}{$\begin{array}{c}\text { Trachea } \\
\text { Diameter } \\
(9) \\
(\mu \mathrm{m}) \\
\end{array}$} & \multirow{3}{*}{$\begin{array}{c}\text { Mesophyll } \\
\text { Thickness } \\
(10) \\
(\mu \mathrm{m})\end{array}$} & \\
\hline & & $\begin{array}{l}\text { Bundle } \\
\text { Sheath }\end{array}$ & Sclerenchyma & L (5) X W (6) & & & & & \\
\hline & $(\mu \mathrm{m})$ & (3) & (4) & $(\mu \mathrm{m})$ & & & & & \\
\hline $\mathrm{T} 1$ & $9.13 \pm 0.16 \mathrm{c} X 5.02 \pm 0.22 b c$ & present & absent & $67.15 \pm 2.45 \mathrm{f} X 59.48 \pm 3.18 \mathrm{~h}$ & $44.16 \pm 2.08 \mathrm{de}$ & $5.16 \pm 0.54 \mathrm{~d}$ & $3.17 \pm 0.12 \mathrm{c}$ & $999.23 \pm 4.04 \mathrm{~g}$ & 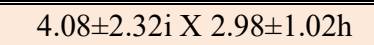 \\
\hline $\mathrm{T} 2$ & $6.71 \pm 2.14$ ef X $3.41 \pm 0.14 \mathrm{c}$ & present & absent & $64.05 \pm 0.15 \mathrm{~g} \times 62.17 \pm 0.21 \mathrm{~h}$ & $32.59 \pm 0.19 \mathrm{~h}$ & $11.04 \pm 0.22 \mathrm{a}$ & $2.24 \pm 0.08 \mathrm{~d}$ & $108.75 \pm 2.72 \mathrm{e}$ & $4.12 \pm 1.08 \mathrm{i} \times 6.02 \pm 0.51 \mathrm{e}$ \\
\hline $\mathrm{T} 3$ & $28.12 \pm 4.91$ a X $7.19 \pm 2.03 b$ & present & absent & $59.74 \pm 0.26 \mathrm{~h} \times 47.25 \pm 1.09 \mathrm{k}$ & $20.42 \pm 0.37 i$ & $9.05 \pm 0.33 \mathrm{a}$ & $4.12 \pm 0.22 \mathrm{a}$ & $115.32 \pm 0,29 d$ & $18.26 \pm 4.97 \mathrm{~b} \times 4.35 \pm 0.24 \mathrm{fg}$ \\
\hline $\mathrm{T} 4$ & $24.27 \pm 2.75 b$ X $6.17 \pm 1.98 b c$ & absent & absent & $61.47 \pm 2.15 \mathrm{~h}$ X $65.79 \pm 1.35 \mathrm{~g}$ & $29.27 \pm 0.98 \mathrm{~h}$ & $7.16 \pm 0.28 \mathrm{ab}$ & $3.15 \pm 0.11 \mathrm{c}$ & $103.95 \pm 4.17 f$ & $69.77 \pm 10.98 \mathrm{a} X 6.14 \pm 0.22 \mathrm{de}$ \\
\hline T5 & $6.18 \pm 0.39 \mathrm{e} X 4.27 \pm 1.45 \mathrm{bc}$ & present & absent & $58.45 \pm 2.21 \mathrm{~h} \mathrm{X} 51.12 \pm 1.23 \mathrm{j}$ & $31.04 \pm 1.17 \mathrm{~h}$ & $3.11 \pm 1.74 \mathrm{de}$ & $3.01 \pm 0,09 \mathrm{c}$ & $98.14 \pm 0.21 \mathrm{~g}$ & $6.78 \pm 0.25 \mathrm{~h} \mathrm{X} 6.54 \pm 0.65 \mathrm{de}$ \\
\hline T6 & $5.17 \pm 0.22 \mathrm{ef} \times 7.11 \pm 0.19 \mathrm{~b}$ & present & absent & $62.17 \pm 1.01 \mathrm{~h} \mathrm{X} \mathrm{82.24 \pm 1.18c}$ & $45.16 \pm 0.54 \mathrm{~d}$ & $4.17 \pm 0.24 \mathrm{e}$ & $2.22 \pm 0.36 \mathrm{~d}$ & $79.16 \pm 1.23 \mathrm{hi}$ & $4.98 \pm 0.33 \mathrm{i} X 7.11 \pm 0.31 \mathrm{~d}$ \\
\hline $\mathrm{T} 7$ & $5.42 \pm 0.16 \mathrm{e}$ X $5.21 \pm 0.11 \mathrm{bc}$ & present & absent & $50.12 \pm 1.07 \mathrm{k} X \quad 46.22 \pm 0.89 \mathrm{k}$ & $42.07 \pm 0.56 \mathrm{e}$ & $5.63 \pm 0.21 \mathrm{~d}$ & $3.07 \pm 0.15 \mathrm{c}$ & $105.18 \pm 0.21 \mathrm{f}$ & $9.44 \pm 0.12 \mathrm{e} X 6.25 \pm 0.16 \mathrm{de}$ \\
\hline $\mathrm{T} 8$ & $10.22 \pm 2.01 \mathrm{de} X 5.08 \pm 0.25 \mathrm{bc}$ & absent & present & $95.91 \pm 2.16 \mathrm{a} X 68.24 \pm 0.98 \mathrm{f}$ & $20.16 \pm 0.15 \mathrm{i}$ & $4.01 \pm 0.12 \mathrm{e}$ & $1.15 \pm 0.04 \mathrm{f}$ & $108.11 \pm 0.34 \mathrm{e}$ & $6.35 \pm 0.29 \mathrm{i} X 2.56 \pm 0.14 \mathrm{~h}$ \\
\hline T9 & $7.72 \pm 2.03 \mathrm{e} X 3.28 \pm 1.35 \mathrm{c}$ & present & present & $91.14 \pm 2.54 \mathrm{~b} X 70.46 \pm 1.14 \mathrm{e}$ & $36.15 \pm 0.44 \mathrm{~g}$ & $5.18 \pm 0.10 \mathrm{~d}$ & $1.19 \pm 0.06 \mathrm{ef}$ & $107.08 \pm 0.97 \mathrm{ef}$ & $5.04 \pm 0.22 \mathrm{i} X 3.03 \pm 0.18 \mathrm{~h}$ \\
\hline $\mathrm{T} 10$ & $8.91 \pm 0.26 \mathrm{e} X 3.25 \pm 0.12 \mathrm{c}$ & present & absent & $87.14 \pm 0.33$ c X $56.59 \pm 0.89 h$ & $60.18 \pm 0.35 \mathrm{a}$ & $9.21 \pm 2.09 \mathrm{a}$ & $2.34 \pm 0.11 \mathrm{~d}$ & $101.12 \pm 3.79 \mathrm{fg}$ & $8.72 \pm 0.07 f \times 3.21 \pm 0.08 \mathrm{~h}$ \\
\hline T11 & $3.21 \pm 0.21 \mathrm{~g} \mathrm{X} 5.16 \pm 0.17 \mathrm{bc}$ & present & absent & $54.45 \pm 0.14 \mathrm{i} X \quad 45.18 \pm 0.271$ & $39.47 \pm 2.15 \mathrm{ef}$ & $4.18 \pm 0.14 \mathrm{e}$ & $2.02 \pm 0.08 \mathrm{~d}$ & $137.27 \pm 4.13 b$ & $3.49 \pm 0.16 \mathrm{i} X \quad 5.64 \pm 0.22 \mathrm{e}$ \\
\hline $\mathrm{T} 12$ & $5.19 \pm 0.27 f \times 3.25 \pm 0.16 c$ & present & absent & $51.17 \pm 1.17 \mathrm{k} \mathrm{X} 81.14 \pm 0.21 \mathrm{~cd}$ & $46.28 \pm 0.44 d$ & $6.17 \pm 0.46 b c$ & $1.39 \pm 0.18 \mathrm{e}$ & $126.39 \pm 2.12 \mathrm{c}$ & $10.69 \pm 0.27 \mathrm{~d} X 6.75 \pm 0.17 \mathrm{de}$ \\
\hline $\mathrm{T} 13$ & $4.71 \pm 0.26 f \times 7.49 \pm 0.22 b$ & absent & absent & $69.27 \pm 0.59$ ef X $53.81 \pm 1.34 \mathrm{i}$ & $43.19 \pm 1.18 \mathrm{de}$ & $5.21 \pm 0.11 \mathrm{~d}$ & $1.27 \pm 0.07 \mathrm{e}$ & $99.18 \pm 1.17$ fg & $4.27 \pm 0.12 \mathrm{i}$ X $6.51 \pm 0.14 \mathrm{de}$ \\
\hline T14 & $6.28 \pm 0.21$ e X $4.57 \pm 0.16 c$ & present & absent & $81.57 \pm 0.28 \mathrm{~d} X 50.24 \pm 0.11 \mathrm{j}$ & $41.19 \pm 0.27 \mathrm{f}$ & $5.67 \pm 0.22 \mathrm{~d}$ & $2.18 \pm 0.04 \mathrm{~d}$ & $110.25 \pm 0.22 \mathrm{e}$ & $6.52 \pm 0.25 \mathrm{i} \times 4.86 \pm 0.36 \mathrm{f}$ \\
\hline T15 & $10.65 \pm 0.44$ de X $6.79 \pm 0.52 b$ & present & absent & $70.56 \pm 0.87 \mathrm{e} X 88.95 \pm 1.96 \mathrm{~b}$ & $48.56 \pm 1.85 b c$ & $7.19 \pm 0.26 \mathrm{ab}$ & $2.38 \pm 0.06 \mathrm{~d}$ & $102.91 \pm 0.98 \mathrm{f}$ & $21.16 \pm 0.08 \mathrm{~b} X 16.35 \pm 2.32 \mathrm{~b}$ \\
\hline T16 & $7.12 \pm .23 \mathrm{e} X 11.47 \pm 0.33 \mathrm{a}$ & present & absent & $68.79 \pm 1.45$ ef X $102.41 \pm 1.22 \mathrm{a}$ & $40.11 \pm 0.41 \mathrm{f}$ & $4.56 \pm 0.21 \mathrm{e}$ & $3.77 \pm 0.11 \mathrm{~b}$ & $65.22 \pm 2.18 \mathrm{i}$ & $8.23 \pm 0.41 \mathrm{~g} \mathrm{X} 23.23 \pm 0.94 \mathrm{a}$ \\
\hline T17 & $12.11 \pm 0.89 \mathrm{~d} \times 6.22 \pm 0.41 \mathrm{~b}$ & present & absent & $90.53 \pm 2.11 \mathrm{~b} \times 51.48 \pm 0.99 \mathrm{j}$ & $45.29 \pm 1.33 \mathrm{~d}$ & $5.11 \pm 0.33 \mathrm{de}$ & $2.56 \pm 0.29 \mathrm{~cd}$ & $152.31 \pm 3.32 \mathrm{a}$ & $6.65 \pm 0.33$ hi X $5.14 \pm 0.17 f$ \\
\hline $\mathrm{T} 18$ & $20.15 \pm 0.77 \mathrm{c} X 7.14 \pm 0.30 \mathrm{~b}$ & absent & present & $61.82 \pm 1.33 \mathrm{~h} \mathrm{X} 82.46 \pm 0.85 \mathrm{c}$ & $52.35 \pm 2.77 \mathrm{~b}$ & $8.27 \pm 0.92 \mathrm{a}$ & $3.02 \pm 0.35 \mathrm{c}$ & $80.54 \pm 1.08 \mathrm{~h}$ & $12.05 \pm 0.19 \mathrm{c} X 8.75 \pm 0.33 \mathrm{c}$ \\
\hline T19 & $10.63 \pm 0.19$ de X $5.27 \pm 0.27 b c$ & present & present & $53.13 \pm 0.39 \mathrm{j} X 46.29 \pm 0.45 \mathrm{kl}$ & $35.84 \pm 0.95 \mathrm{~g}$ & $6.28 \pm 0.19 b$ & $2.11 \pm 0.12 \mathrm{~d}$ & $97.35 \pm 1.54 \mathrm{~g}$ & $8.19 \pm 0.21 \mathrm{~g} \mathrm{X} 6.28 \pm 0.22 \mathrm{de}$ \\
\hline
\end{tabular}


Table 3. Characteristics of leaf surface patterns of the examined taxa. Outcomes represent mean values \pm standard deviation; means with different letters are significant at $p=0.05$ level (Duncan's multiple-range test), for taxa abbreviations see Table 1 (L: Length, W: Width).

\begin{tabular}{|c|c|c|c|c|c|c|c|c|c|c|c|c|}
\hline \multirow{4}{*}{ Taxa } & \multicolumn{6}{|c|}{ Adaxial epidermis } & \multicolumn{6}{|c|}{ Abaxial epidermis } \\
\hline & \multirow{3}{*}{$\begin{array}{c}\begin{array}{c}\text { Anticlinal } \\
\text { cell wall }\end{array} \\
\text { (13) }\end{array}$} & \multirow{3}{*}{$\begin{array}{c}\text { Shape of } \\
\text { epidermal } \\
\text { cells } \\
\\
(14)\end{array}$} & \multicolumn{4}{|c|}{ Stomata } & \multirow{2}{*}{$\begin{array}{c}\text { Anticlinal } \\
\text { cell wall }\end{array}$} & \multirow{2}{*}{$\begin{array}{l}\text { Shape of } \\
\text { epidermal } \\
\text { cells }\end{array}$} & \multicolumn{4}{|c|}{ Stomata } \\
\hline & & & $\begin{array}{c}\mathbf{L} \\
(\mu \mathrm{m})\end{array}$ & $\begin{array}{c}\text { W } \\
(\mu \mathrm{m})\end{array}$ & $\begin{array}{l}\text { Number } \\
\text { per } \text { mm }^{2}\end{array}$ & Index & & & $\begin{array}{c}\mathbf{L} \\
(\mu \mathrm{m})\end{array}$ & $\begin{array}{c}\text { W } \\
(\mu \mathrm{m})\end{array}$ & $\begin{array}{l}\text { Number } \\
\text { per } \mathbf{m m}^{2}\end{array}$ & Index \\
\hline & & & (15) & (16) & (17) & (18) & (19) & (20) & (21) & (22) & (23) & (24) \\
\hline $\mathrm{T} 1$ & Undulated & Irregular & $30.76 \pm 1.21 \mathrm{~g}$ & $21.22 \pm 0.76 \mathrm{j}$ & $81 \pm 2 c$ & $33.19 \pm 0.15 \mathrm{ef}$ & Undulated & Irregular & $27.29 \pm 0.89 \mathrm{i}$ & $20.96 \pm 0.44 h$ & $36 \pm 4 f$ & $31.45 \pm 0.18 \mathrm{de}$ \\
\hline $\mathrm{T} 2$ & Sinuate & Irregular & $30.22 \pm 0.37 \mathrm{~g}$ & $19.27 \pm 0.221 \mathrm{~m}$ & $36 \pm 2 g$ & $28.68 \pm 0.27 \mathrm{~h}$ & Sinuate & Irregular & $25.05 \pm 0.33 \mathrm{jk}$ & $19.16 \pm 0.31 \mathrm{j}$ & $27 \pm 2 g$ & $22.63 \pm 0.09 \mathrm{i}$ \\
\hline $\mathrm{T} 3$ & Undulated & Irregular & $22.14 \pm 0.23 \mathrm{k}$ & $17.42 \pm 0.33 n$ & $36 \pm 2 g$ & $12.37 \pm 0.11 \mathrm{p}$ & Sinuate & Irregular & $21.23 \pm 0.261$ & $16.98 \pm 0.22 \mathrm{k}$ & $27 \pm 4 g$ & $10.89 \pm 0.32 p$ \\
\hline $\mathrm{T} 4$ & Undulated & Polygonal & $26.51 \pm 0.17 \mathrm{j}$ & $20.05 \pm 0.12 \mathrm{jk}$ & $45 \pm 2 f$ & $34.62 \pm 0.15 \mathrm{~d}$ & Undulated & Polygonal & $32.17 \pm 0.28 \mathrm{e}$ & $21.12 \pm 0.11 \mathrm{~h}$ & $36 \pm 2 f$ & $21.96 \pm 0.25 \mathrm{j}$ \\
\hline $\mathrm{T} 5$ & Undulated & Irregular & $30.89 \pm 0.25 \mathrm{~g}$ & $16.18 \pm 0.31 \mathrm{o}$ & $99 \pm 2 b$ & $63.01 \pm 0.08 \mathrm{a}$ & Undulated & Irregular & $29.17 \pm 0.22 \mathrm{~g}$ & $18.02 \pm 0.15 \mathrm{k}$ & $90 \pm 2 \mathrm{a}$ & $51.55 \pm 0.20 \mathrm{a}$ \\
\hline T6 & Undulated & Polygonal & $31.15 \pm 0.22 \mathrm{~g}$ & $24.28 \pm 0.35 n$ & $135 \pm 5 \mathrm{a}$ & $48.76 \pm 0.24 b$ & Straight & Rectangular & $27.62 \pm 0.37 \mathrm{i}$ & $20.19 \pm 0.23 \mathrm{i}$ & $36 \pm 4 f$ & $27.16 \pm 0.12 \mathrm{fg}$ \\
\hline $\mathrm{T} 7$ & Undulated & Irregular & $34.53 \pm 0.44 \mathrm{f}$ & $22.62 \pm 0.23 \mathrm{i}$ & $45 \pm 2 f$ & $33.33 \pm 0.15 \mathrm{ef}$ & $\begin{array}{l}\text { Straight or } \\
\text { Undulated }\end{array}$ & Irregular & $26.44 \pm 0.18 \mathrm{j}$ & $16.48 \pm 0.29 \mathrm{kl}$ & $18 \pm 2 \mathrm{~h}$ & $10.18 \pm 0.28 \mathrm{r}$ \\
\hline $\mathrm{T} 8$ & Undulated & Irregular & $38.56 \pm 0.37 \mathrm{~d}$ & $24.51 \pm 0.26 \mathrm{~h}$ & $72 \pm 4 \mathrm{~cd}$ & $44.15 \pm 0.33 \mathrm{~g}$ & Undulated & Irregular & $31.28 \pm 0.51 \mathrm{ef}$ & $19.27 \pm 0.41 \mathrm{j}$ & $45 \pm 4 \mathrm{e}$ & $20.11 \pm 0.151$ \\
\hline T9 & Undulated & Irregular & $36.41 \pm 0.20 \mathrm{e}$ & $22.78 \pm 0.39 \mathrm{i}$ & $82 \pm 4 c$ & $32.05 \pm 0.13 \mathrm{e}$ & Straight & Polygonal & $26.11 \pm 0.79 \mathrm{ij}$ & $21.03 \pm 0.38 \mathrm{~h}$ & $65 \pm 3 c$ & $21.21 \pm 0.18 \mathrm{k}$ \\
\hline $\mathrm{T} 10$ & Undulated & Polygonal & $28.16 \pm 0.39 \mathrm{hi}$ & $25.67 \pm 0.20 \mathrm{~g}$ & $74 \pm 5 \mathrm{~cd}$ & $33.87 \pm 0.41 \mathrm{e}$ & Undulated & Polygonal & $30.14 \pm 0.25 \mathrm{~g}$ & $23.09 \pm 0.30 \mathrm{f}$ & $40 \pm 4 \mathrm{ef}$ & $25.29 \pm 0.10 \mathrm{~h}$ \\
\hline $\mathrm{T} 11$ & Straight & Polygonal & $29.75 \pm 0.16 \mathrm{~g}$ & $19.49 \pm 0.141$ & $40 \pm 4 \mathrm{efg}$ & $18.41 \pm 0.30 \mathrm{o}$ & $\begin{array}{l}\text { Straight or } \\
\text { Undulated }\end{array}$ & Polygonal & $26.38 \pm 0.11 \mathrm{i}$ & $19.27 \pm 0.08 \mathrm{j}$ & $10 \pm 2 \mathrm{i}$ & $12.58 \pm 0.27 \mathrm{o}$ \\
\hline $\mathrm{T} 12$ & Undulated & Irregular & $28.54 \pm 0.33 \mathrm{~h}$ & $21.16 \pm 0.25 \mathrm{j}$ & $80 \pm 6 c$ & $20.84 \pm 0.27 \mathrm{mn}$ & Sinuate & Irregular & $25.17 \pm 0.14 \mathrm{j}$ & $21.04 \pm 0.47 \mathrm{~h}$ & $70 \pm 4 b c$ & $32.29 \pm 0.41 \mathrm{~d}$ \\
\hline $\mathrm{T} 13$ & Undulated & Irregular & $25.89 \pm 0.11 \mathrm{jk}$ & $21.41 \pm 0.17 \mathrm{j}$ & $51 \pm 3 \mathrm{e}$ & $18.76 \pm 0.19$ no & $\begin{array}{l}\text { Straight or } \\
\text { Undulated }\end{array}$ & Polygonal & $27.09 \pm 0.23 \mathrm{i}$ & $29.45 \pm 0.51 \mathrm{c}$ & $75 \pm 5 b$ & $27.61 \pm 0.24 f$ \\
\hline $\mathrm{T} 14$ & Undulated & Irregular & $40.16 \pm 0.25 \mathrm{c}$ & $28.14 \pm 0.26 \mathrm{~d}$ & $74 \pm 2 \mathrm{~cd}$ & $27.46 \pm 0.21 \mathrm{i}$ & Straight & Polygonal & $38.27 \pm 0.11 \mathrm{~d}$ & $25.38 \pm 0.34 d$ & $76 \pm 2 b$ & $30.55 \pm 0.12 \mathrm{e}$ \\
\hline $\mathrm{T} 15$ & Sinuate & Irregular & $38.41 \pm 0.35 \mathrm{~d}$ & $27.36 \pm 0.23 \mathrm{e}$ & $51 \pm 4 \mathrm{e}$ & $23.19 \pm 0.161$ & Sinuate & Irregular & $24.75 \pm 0.21 \mathrm{k}$ & $20.77 \pm 0.18 \mathrm{~h}$ & $45 \pm 4 \mathrm{e}$ & $19.80 \pm 0.14 \mathrm{~m}$ \\
\hline T16 & Undulated & Irregular & $41.07 \pm 0.14 b c$ & $26.61 \pm 0.35 f$ & $100 \pm 4 b$ & $38.59 \pm 0.33 \mathrm{c}$ & Undulated & Irregular & $38.99 \pm 0.14 \mathrm{c}$ & $25.23 \pm 0.39 \mathrm{de}$ & $36 \pm 4 \mathrm{ef}$ & $33.33 \pm 0.19 \mathrm{c}$ \\
\hline T17 & Undulated & Irregular & $42.21 \pm 0.29 b$ & $33.15 \pm 0.26 \mathrm{~b}$ & $47 \pm 2 \mathrm{ef}$ & $20.98 \pm 0.22 \mathrm{~m}$ & Sinuate & Irregular & $45.40 \pm 0.30 \mathrm{~b}$ & $42.01 \pm 0.11 \mathrm{a}$ & $40 \pm 2 \mathrm{ef}$ & $21.08 \pm 0.27 \mathrm{kl}$ \\
\hline $\mathrm{T} 18$ & Undulated & Irregular & $45.10 \pm 0.11 \mathrm{a}$ & $39.08 \pm 0.22 \mathrm{a}$ & $70 \pm 4 \mathrm{~cd}$ & $24.51 \pm 0.08 \mathrm{k}$ & Undulated & Irregular & $46.34 \pm 0.33 \mathrm{a}$ & $41.24 \pm 0.35 b$ & $24 \pm 2 \mathrm{~g}$ & $15.52 \pm 0.35 n$ \\
\hline T19 & Undulated & Irregular & $31.79 \pm 0.18 \mathrm{~g}$ & $31.17 \pm 0.15 \mathrm{c}$ & $72 \pm 2 \mathrm{~cd}$ & $25.49 \pm 0.15 \mathrm{j}$ & Undulated & Irregular & $28.47 \pm 0.11 \mathrm{~h}$ & $22.62 \pm 0.27 \mathrm{fg}$ & $60 \pm 4 \mathrm{~cd}$ & $40.11 \pm 0.46 \mathrm{~b}$ \\
\hline
\end{tabular}


Table 4. Anatomical characteristics of stems of the examined taxa. Outcomes represent mean values \pm standard deviation; means with different letters are significant at $\mathrm{p}=0.05$ level (Duncan's multiple-range test), for taxa abbreviations see Table 1 (L: Length, W: Width).

\begin{tabular}{|c|c|c|c|c|c|c|c|c|c|}
\hline \multirow[b]{2}{*}{ Taxa } & \multicolumn{2}{|c|}{ Epidermis cells } & \multirow{2}{*}{$\begin{array}{c}\text { Cortex } \\
\text { Thickness } \\
(\mu \mathrm{m}) \\
(28) \\
\end{array}$} & \multicolumn{2}{|c|}{ Endodermis cells } & \multicolumn{2}{|r|}{ Vascular bundles } & \multirow{2}{*}{$\begin{array}{l}\text { Interfascicular } \\
\text { region } \\
(35)\end{array}$} & \multirow{2}{*}{$\begin{array}{c}\text { Scleranchymatic } \\
\text { region } \\
\text { thickness } \\
(36)\end{array}$} \\
\hline & $\begin{array}{c}\text { Structure } \\
\text { (25) }\end{array}$ & $\begin{array}{c}\mathbf{L}(26) \underset{(\mu \mathrm{m})}{X} \mathbf{W}(27) \\
\end{array}$ & & $\begin{array}{c}\text { Structure } \\
\text { (29) }\end{array}$ & $\begin{array}{c}\mathrm{L}(30) \mathrm{X} \mathrm{W}(\mathbf{3 1}) \\
(\mu \mathrm{m})\end{array}$ & $\begin{array}{c}\text { Number } \\
\text { (32) }\end{array}$ & $\begin{array}{c}\text { Sizes } \\
\text { L(33) X W(34) }\end{array}$ & & \\
\hline $\mathrm{T} 1$ & flat cells & $14.16 \pm 0.59 \mathrm{~b} \times 9.81 \pm 0.12 \mathrm{~b}$ & $59.45 \pm 0.97 \mathrm{e}$ & large flat cells & $12.14 \pm 1.45 \mathrm{~h} \mathrm{X} \mathrm{5.66 \pm 0.19fg}$ & $10-12 b$ & $104.13 \pm 0.78 f$ X $41.22 \pm 0.44 \mathrm{~m}$ & clearly & $102.45 \pm 1.56 \mathrm{a}$ \\
\hline $\mathrm{T} 2$ & rectangular cells & $9.87 \pm 0.22 \mathrm{~d} \times 7.65 \pm 0.18 \mathrm{~d}$ & $74.59 \pm 0.81 \mathrm{c}$ & flat cells & $9.88 \pm 0.55 \mathrm{i} X \quad 4.99 \pm 1.11 \mathrm{fg}$ & $9-10 b c$ & $95.18 \pm 2.07 \mathrm{~g} \mathrm{X} 48.46 \pm 1.221$ & clearly & $60.48 \pm 1.97 \mathrm{e}$ \\
\hline $\mathrm{T} 3$ & flat cells & $10.83 \pm 0.22 \mathrm{~d} X 5.96 \pm 0.21 \mathrm{~g}$ & $14.46 \pm 0.161$ & large flat cells & $15.12 \pm 0.21 \mathrm{f} X 8.26 \pm 0.14 \mathrm{c}$ & $6-8 d$ & $107.19 \pm 2.23$ e X $60.85 \pm 1.54 \mathrm{k}$ & unclearly & $43.41 \pm 1.05 \mathrm{i}$ \\
\hline $\mathrm{T} 4$ & square-shaped cells & $5.02 \pm 0.21 \mathrm{k} \mathrm{X} 4.84 \pm 0.19 \mathrm{ij}$ & $48.74 \pm 2.10 \mathrm{fg}$ & large flat cells & $12.87 \pm 0.12 \mathrm{~h} \mathrm{X} 6.12 \pm 0.23 \mathrm{f}$ & $14-16 a$ & $110.54 \pm 0.88 \mathrm{~d} \times 68.96 \pm 2.05 \mathrm{j}$ & unclearly & $48.91 \pm 0.88 \mathrm{~h}$ \\
\hline T5 & thick-walled flat cells & $8.77 \pm 0.22 \mathrm{f} X 4.09 \pm 0.37 \mathrm{k}$ & $39.10 \pm 1.14 \mathrm{~h}$ & $\begin{array}{l}1 \text { or } 2 \text { seriate } \\
\text { large flat cells }\end{array}$ & $24.05 \pm 1.22 b$ X $8.74 \pm 0.44 b c$ & $5-6 \mathrm{de}$ & $102.85 \pm 0.77 \mathrm{fg} X 83.24 \pm 1.33 \mathrm{~h}$ & clearly & $31.14 \pm 0.631$ \\
\hline T6 & flat cells & $5.48 \pm 0.21 \mathrm{j} X 3.91 \pm 0.12 \mathrm{k}$ & $52.46 \pm 1.08 \mathrm{f}$ & large flat cells & $12.05 \pm 0.19 \mathrm{~h} X 7.43 \pm 0.10 \mathrm{~d}$ & $7-9 \mathrm{~cd}$ & $106.11 \pm 1.54$ ef X $102.85 \pm 0.77 \mathrm{de}$ & unclearly & $82.41 \pm 3.46 \mathrm{~cd}$ \\
\hline $\mathrm{T} 7$ & thick-walled flat cells & $10.63 \pm 0.12 \mathrm{~d} \times 6.32 \pm 0.16 \mathrm{f}$ & $25.61 \pm 0.49 \mathrm{k}$ & flat cells & $28.75 \pm 0.86 \mathrm{a} X 6.99 \pm 0.21 \mathrm{e}$ & $5-6 \mathrm{de}$ & $108.77 \pm 1.21 \mathrm{de} X 112.86 \pm 0.86 \mathrm{c}$ & clearly & $34.78 \pm 2.46 \mathrm{k}$ \\
\hline $\mathrm{T} 8$ & thick-walled flat cells & $7.55 \pm 0.86 \mathrm{~g} \times 5.31 \pm 0.12 \mathrm{~h}$ & $105.46 \pm 0.27 b$ & large flat cells & $14.73 \pm 0.92 \mathrm{f} X 6.02 \pm 0.12 \mathrm{f}$ & $8-9 \mathrm{~cd}$ & $70.53 \pm 1.32 \mathrm{k} X 105.09 \pm 1.27 \mathrm{~d}$ & unclearly & $48.97 \pm 2.13 \mathrm{~h}$ \\
\hline T9 & $\begin{array}{l}\text { thick-walled square- } \\
\text { shaped cells }\end{array}$ & $6.96 \pm 0.12 \mathrm{hi}$ X $6.59 \pm 0.24 \mathrm{ef}$ & $38.76 \pm 0.95 \mathrm{hi}$ & large flat cells & $18.65 \pm 0.26 \mathrm{e} X 7.83 \pm 0.15 \mathrm{c}$ & $12-14 a b$ & $77.85 \pm 0.92 \mathrm{j} X 40.62 \pm 0.77 \mathrm{~m}$ & clearly & - \\
\hline $\mathrm{T} 10$ & flat cells & $8.07 \pm 0.22 \mathrm{~g} \mathrm{X} 4.88 \pm 0.08 \mathrm{ij}$ & $44.61 \pm 0.74 \mathrm{~g}$ & flat cells & $9.41 \pm 0.17 \mathrm{i} \times 3.84 \pm 0.34 \mathrm{~g}$ & $10-12 b$ & $81.50 \pm 3.17 \mathrm{ij} \mathrm{X} 46.41 \pm 2.911$ & unclearly & $54.64 \pm 0.89 \mathrm{~g}$ \\
\hline T11 & square-shaped cells & $9.21 \pm 0.22$ de X $8.94 \pm 0.11 \mathrm{c}$ & $116.85 \pm 2.38 \mathrm{a}$ & flat cells & $14.15 \pm 0.22 \mathrm{fg}$ X $12.87 \pm 0.25 \mathrm{a}$ & $5-6 \mathrm{de}$ & $124.41 \pm 1.47 \mathrm{~b} \times 156.06 \pm 2.85 \mathrm{a}$ & unclearly & $83.55 \pm 1.14 \mathrm{c}$ \\
\hline $\mathrm{T} 12$ & flat cells & $10.23 \pm 0.84 \mathrm{~d} \times 7.49 \pm 0.13 \mathrm{~d}$ & $37.45 \pm 0.51 \mathrm{i}$ & flat cells & $14.66 \pm 0.31 \mathrm{fg} X \quad 6.54 \pm 0.21 \mathrm{ef}$ & $10-12 b$ & $84.66 \pm 0.77 \mathrm{i} X 59.52 \pm 0.65 \mathrm{k}$ & clearly & $46.11 \pm 0.39 \mathrm{hi}$ \\
\hline $\mathrm{T} 13$ & flat cells & $19.16 \pm 0.36 \mathrm{a} X 6.78 \pm 0.21 \mathrm{ef}$ & $42.75 \pm 0.36 \mathrm{~h}$ & large flat cells & $25.16 \pm 0.24 b$ X $7.42 \pm 0.21 d$ & $6-8 d$ & $104.11 \pm 2.51 \mathrm{fg} X 124.04 \pm 1.08 \mathrm{~b}$ & clearly & $39.41 \pm 0.65 \mathrm{j}$ \\
\hline $\mathrm{T} 14$ & thick-walled flat cells & $12.16 \pm 0.17 \mathrm{c} \mathrm{X} 6.88 \pm 0.27 \mathrm{e}$ & $49.56 \pm 0.21 \mathrm{f}$ & large flat cells & $15.08 \pm 0.21 \mathrm{f} X 8.27 \pm 0.15 \mathrm{c}$ & $7-9 \mathrm{~cd}$ & $123.81 \pm 1.24 \mathrm{bc} X 91.73 \pm 0.85 \mathrm{~g}$ & unclearly & $97.44 \pm 0.86 b$ \\
\hline T15 & flat cells & $9.54 \pm 0.12 \mathrm{~d} \times 6.61 \pm 0.08 \mathrm{f}$ & $47.81 \pm 0.39 \mathrm{f}$ & flat cells & $10.85 \pm 0.33 \mathrm{~h} \mathrm{X} \mathrm{7.21 \pm 0.24de}$ & $10-12 b$ & $95.12 \pm 0.89 \mathrm{~g} \mathrm{X} 74.18 \pm 0.65 \mathrm{i}$ & clearly & - \\
\hline T16 & $\begin{array}{l}\text { elongated rectangular } \\
\text { cells }\end{array}$ & $7.15 \pm 0.25 \mathrm{~h} \mathrm{X} 15.36 \pm 0.16 \mathrm{a}$ & $29.96 \pm 0.37 \mathrm{j}$ & large flat cells & $18.49 \pm 0.22 \mathrm{e} X 9.17 \pm 0.21 \mathrm{~b}$ & $10-12 b$ & $130.84 \pm 0.86 \mathrm{a} X 102.39 \pm 0.77 \mathrm{de}$ & unclearly & - \\
\hline T17 & rectangular cells & $8.47 \pm 0.12 \mathrm{fg} X 5.09 \pm 0.10 \mathrm{hi}$ & $71.25 \pm 2.52 \mathrm{~d}$ & large flat cells & $20.35 \pm 0.12 \mathrm{c} X 7.84 \pm 0.29 \mathrm{c}$ & $9-10 b c$ & $120.54 \pm 2.18 \mathrm{c} X 95.17 \pm 0.72 \mathrm{f}$ & unclearly & $56.22 \pm 0.29 \mathrm{f}$ \\
\hline T18 & rectangular cells & 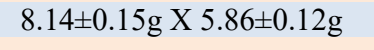 & $58.91 \pm 1.46 \mathrm{e}$ & large flat cells & $20.07 \pm 0.32 \mathrm{~cd} X 8.19 \pm 0.39 \mathrm{c}$ & $7-9 \mathrm{~cd}$ & $106.45 \pm 0.59 \mathrm{e} X 102.16 \pm 0.46 \mathrm{de}$ & clearly & $67.18 \pm 0.37 d$ \\
\hline T19 & thick-walled flat cells & $11.02 \pm 0.12 \mathrm{~d} \times 6.91 \pm 0.15 \mathrm{e}$ & $51.04 \pm 2.32 \mathrm{f}$ & flat cells & $8.07 \pm 0.12 \mathrm{j} X 5.47 \pm 0.12 \mathrm{fg}$ & $10-14 a b$ & $88.43 \pm 0.18 \mathrm{~h} \mathrm{X} 46.63 \pm 0.321$ & clearly & - \\
\hline
\end{tabular}




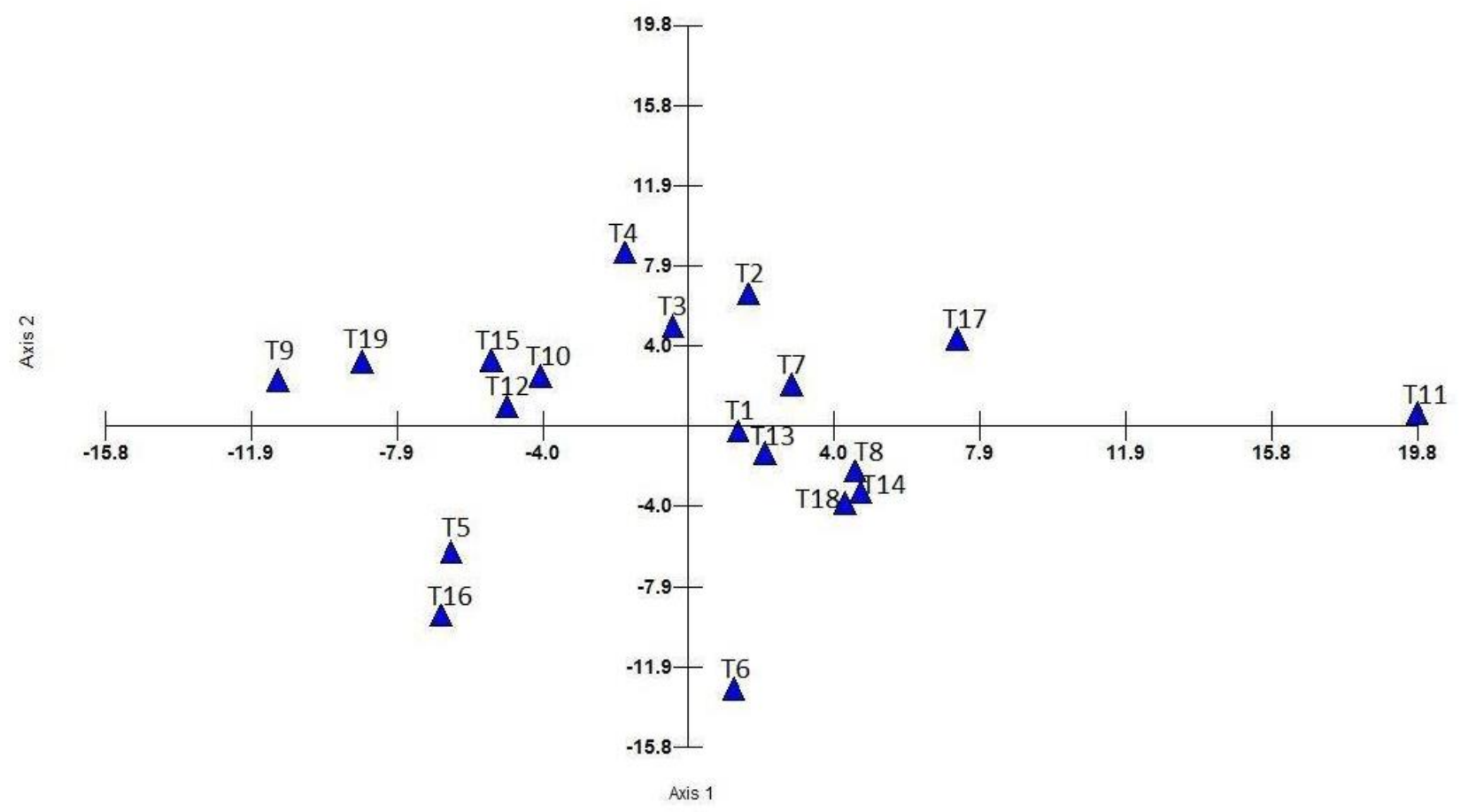

Fig. 6. Principal component analysis of the examined taxa (See Table 1 for taxa abbreviations).

\section{Discussion}

Thlaspi $i$.l. is represented by 36 taxa, including species and subspecies, found in six sections in the Flora of Turkey and the East Aegean Islands (Flora of Turkey) (Hedge 1965, Davis 1988, Yildırımlı 2001). The present work assesses the significance of anatomical characteristics and evaluates the correlations among leaf and stem anatomy. The anatomical structures of the leaves and stems of the examined Thlaspi taxa were investigated in detail for the first time in this study.

Generally, the examined taxa have a unifacial mesophyll, rarely bifacial and made up of 2-5 layers of palisade parenchyma and 3-6 layers of abaxial spongy parenchyma, or equifacial. Metcalfe \& Chalk (1957) formerly found that bifacial mesophyll is most common in the Brassicaceae family, but unifacial, bifacial and equifacial types were commonly observed in the present study. These types of leaf mesophyll, except unifacial, are widespread in correlated genera, such as bifacial in Alyssum L. (Orcan \& Binzet 2002), bifacial and equifacial in Ricotia L. (Selvi \& Paksoy 2013) and bifacial in Aubrieta Adans (Karaismailoğlu 2016).

All but three (T. huetii, T. densiflorum and T. praecox subsp. praecox) of the examined taxa have undulated anticlinal cell walls (Fig. 1). These three taxa (straight or sinuate) grow at low altitudes and humid zones, while the 13 taxa with undulated anticlinal cell walls are found in higher altitudes and arid habitats. According to Stace (1984), epidermal cells with undulated or straight outlines are widespread in xeromorphic and mesomorphic plants. Another study reported that most epidermal cells of leaves in dicotyledons have sinuate anticlinal cell walls, which may be caused by pressure exerted on the walls during cell development (Orcan \& Binzet 2002).

The studied Thlaspi taxa grow at various altitudes between 270 and $2750 \mathrm{~m}$ and in different ecological conditions. While the mesophyll layer in the taxa growing at low altitudes is quite loose, it is denser in appearance of the parenchyma cells at high altitudes. This shows that high altitude and inadequate water can trigger further development of the mesophyll parenchyma, and consequently enhance photosynthetic activity (Fahn 1990, Ozcan et al. 2015).

All the examined taxa are of the amphistomatic type. Stomatal density differs significantly between the abaxial and adaxial surfaces of leaves (Table 3). The density is clearly higher on adaxial surfaces than abaxial surfaces in most of the examined taxa. The exceptions are T12-T14, T17 and T18 taxa, which exhibited the opposite. This result is compatible with several previous studies, including Orcan \& Binzet (2002), Arambarri et al. (2006), Ozcan et al. (2015) and Karaismailoğlu (2016). Stomata are mostly anisocytic (Cruciferae type) or rarely anomocytic (Ranunculaceae type) in the examined taxa. These types of stomata were formerly found in the family Brassicaceae by Metcalfe \& Chalk (1957), Cansaran et al. (2007), Selvi \& Paksoy (2013) and Karaismailoğlu (2016, 2019).

The stems of herbaceous Thlaspi taxa generally produce no secondary tissues. Cortex is composed of flat or circular parenchyma in 3-12 layers. A thick bundle sheath covers the adaxial side of the phloem and xylem. 
All vascular bundles were of the collateral type. The inner part of the pith breaks down in the late or early phases of primary growth, like in some other Brassicaceae family members (Metcalfe \& Chalk 1957).

Yentür (2003) showed that the arrangement of bundles provides useful information in comparative anatomical investigations. The number of vascular bundles in the stem is usually between 5 and 16 and the bundles are arranged in a single ring. Selvi \& Paksoy (2013) and Karaismailoğlu (2016) reported that vascular bundles are distributed in a circular manner in one ring in stems of some Brassicaceae species. Clustered scleranchymatic cells were positioned on the adaxial and abaxial sides of the vascular bundles in most of the examined taxa (Fig. 4), except for T9, T15, T16 and T19 (Fig. 4 and Table 4). The presence or absence of secretory channels is quite significant in comparative anatomical studies (Makbul et al. 2011). Also, the content, distribution and presence or absence of secretory channels were shown to differ among the plant taxa (Milan et al. 2006). This work found that there are a few secretory networks in the stem cortex near the vascular bundles of the examined taxa.

A dendrogram was formed to assess the anatomical characteristics of the leaves and stems of the examined Thlaspi taxa using UPGMA cluster analysis. The dendrogram indicating two major clusters was partially compatible with Hedge (1965), Davis (1988) and Y1ldirımlı (2001), where 36 taxa were placed into six sections. The anatomical differences between the leaves and stems were observed at the species level, but showed no correlation at section level. It seems that anatomical

\section{References}

1. Al-Shehbaz, I.A. 1986. The genera of Lepidieae (Cruciferae; Brassicaceae) in the Southeastern United States. Journal of the Arnold Arboretum, 67: 265-311.

2. Al-Shehbaz, I.A. 2014. A synopsis of the genus Noccaea (Coluteocarpeae, Brassicaceae). Harvard Papers in Botany, 19: 25-51.

3. Al-Shehbaz, I.A., Beilstein, M.A. \& Kellogg, E.A. 2006. Systematics and phylogeny of the Brassicaceae (Cruciferae): an overview. Plant Systematics and Evolution, 259: 89-120.

4. Al-Shehbaz, I.A., Mutlu, B. \& Donmez, A.A. 2007. The Brassicaceae (Cruciferae) of Turkey, Updated. Turkish Journal of Botany, 31: 327-336.

5. Appel, O. \& Al-Shehbaz, I.A. 2003. Brassicaceae. In: Kubitzki, K. \& Bayer, C. (eds) The Families and Genera of Vascular Plants, Vol. 5. Springer, Berlin, 75-174 pp.

6. Arambarri, A.M., Freire, S.E., Colares, M.N., Bayo'N, N.D., Novoa, M.C., Monti, C. \& Stenglein, S.A. 2006. Leaf anatomy of medicinal shrubs and trees from gallery forests of the Paranaense province (Argentina). Bulletin of the Botanical Society of Argentina, 41: 233-268.

7. Artelari, R. 2002. Thlaspi. In: Strid, A. \& Tan, K. (editors), Flora Helenica, Vol. 2. A. R., G. Gantner Verlag, Ruggell. 253-261 pp. features are not in full agreement with the available classification, nevertheless it proves to be valuable data. That is, the anatomical characters of leaves and stems partially supported the features utilized in the distribution of Thlaspi species in The Flora of Turkey.

Principal component analysis can provide data about the variability of the used anatomical characters. The high cumulative variance values of principal components indicate that the characters investigated can be used to elucidate variances among the studied Thlaspi taxa. Dissimilarity ratios among the taxa were defined. Accordingly, the closest relationship was seen between T9 and T19, while the most distant relationship was found between $\mathrm{T} 9$ and $\mathrm{T} 11$.

\section{Conclusion}

This study questions the usefulness of the studied characteristics in the infrageneric delimitation in Thlaspi. The compared anatomical characteristics among the examined Thlaspi taxa are partially in accordance with their sectional delimitation given in The Flora of Turkey. However, the findings showed that new arrangements may be necessary for the systematic positions of some taxa. The leaf and stem anatomical characteristics are helpful for distinctions based on morphology. This study is a preliminary study to determine the usefulness of the examined anatomical characters. Further investigations that include all the taxa of the genus are required to define all variations and obtain a better systematic understanding of the genus.

8. Cansaran, A., Ergen Akcin, E. \& Kandemir, N. 2007. A Study on the Morphology, Anatomy an Autecology of Erysimum amasianum Hausskn. \& Bornm. (Brassicaceae) Distributed in Central Black Sea Region (Amasya-Turkey). The International Journal of Science \& Technology, 2: 1324.

9. Davis, P.H. 1988. Flora of Turkey and the East Aegean Islands, supplement 1. Edinburgh Univ Press, Edinburgh, $680 \mathrm{pp}$.

10. Fahn, A. 1990. Plant Anatomy, 4th edn. Pergamon Press, New York, 588 pp.

11. Greuter, W. \& Raus, T. 1983. Med-Checklist Notulae, 7. Willdenowia, 13: 79-96.

12. Greuter, W., Burdet, H.M. \& Long, G. 1986. MedChecklist. Vol. 3. Conservatoire et Jardin botaniques de la Ville de Genève, Geneva, 395 pp.

13. Hedge, I.C. 1965. Thlaspi. In: Davis, P.H. (ed) Flora of Turkey and the East Aegean Islands. Edinburgh Univ Press, Edinburgh, 330-341 pp.

14. Karaismailoğlu, M.C. 2015a. Morphological and anatomical features of seeds of Turkish Romulea taxa (Iridaceae) and their taxonomic significance. Acta Botanica Croatica, 74: 31-41. 
15. Karaismailoğlu, M.C. 2015b. Morphological and anatomical features of cypsela of some Crepis taxa (Asteraceae) from turkey and their taxonomic importance. Pakistan Journal of Botany, 47: 1473-1480.

16. Karaismailoğlu, M.C. 2016. Addition to characters of endemic Aubrieta canescens subsp. canescens Bornm. (Brassicaceae) from Turkey. Bangladesh Journal of Botany, 45: 509-515.

17. Karaismailoğlu, M.C. 2019. Taxonomical, morphological, palynological, anatomical and ecological investigations on monotypic genus Pachyphragma from Turkey. Pakistan Journal of Botany, 51: 1021-1026.

18. Karaismailoğlu, M.C. \& Erol, O. 2018. Seed structure and its taxonomic implications for genus Thlaspi sensu lato sections Nomisma, Thlaspi, and Pterotropis (Brassicaceae). Turkish Journal of Botany, 42: 591-609.

19. Karaismailoğlu, M.C. \& Erol, O. 2019. Pollen morphology of some taxa of Thlaspi L. sensu lato (Brassicaceae) from Turkey, and its taxonomical importance. Palynology, 42: 244-254.

20. Karaismailoğlu, M.C. \& Güner, Ö. 2019. Nutlet structures of subsection Fragiles of the genus Stachys (Lamiaceae) from Turkey and their systematic applications. Turkish Journal of Botany, 43: 659-672.

21. Koch, M., Mummenhoff, K. \& Hurka, H. 1998. Molecular biogeography and evolution of the Microthlaspi perfoliatum s.l. polyploid complex (Brassicaceae): chloroplast DNA and nuclear ribosomal DNA restriction site variation. Canadian Journal of Botany, 76: 382-396.

22. Koch, M., Haubold, B. \& Mitchell-olds, T. 2001. Molecular systematics of the Brassicaceae: evidence from coding plastidic mat $\mathrm{K}$ and nuclear chs sequences. American Journal of Botany, 88: 534-544.

23. Kovach, W.L. 2007. MVSP - A MultiVariate Statistical Package for Windows, ver. 3.1. Kovach Computing Services, Wales.

24. Liu, W. \& Zhu, X.Y. 2011. Leaf epidermal characters and taxonomic revision of Schizophragma and Pileostegia (Hydrangeaceae). Botanical Journal of the Linnean Society, 165: 285-314.

25. Makbul, S., Coskuncelebi, K. \& Beyazoğlu, O. 2011. Notes on the stem anatomy of Scorzonera (Asteraceae) taxa from Northeast Turkey. Phytologica Balcanica, 17: 113-121.

26. Metcalfe, C.R. \& Chalk, L. 1957. Anatomy of the Dicotyledons (Leaves, Stem and Wood in Relation to Taxonomy with Notes on Economic Uses), Vol. 1. Oxford University Press, London, 1500 pp.

27. Meyer, F.K. 1973. Conspectus der "Thlaspi"-Arten Europas, Afrikas und Vorderasiens. Feddes Repertorium, 84: 449-470.

28. Meyer, F.K. 1979. Kritische Revision der "Thlaspi"-Arten Europas, Afrikas und Vorderasiens. I. Geschichte, Morphologie und Chorologie. Feddes Repertorium, 90: 129-54.
29. Meyer, F.K. 1991. Seed-coat anatomy as a character for a new classification of Thlaspi. Flora Vegetation Mundi, 9: $9-15$.

30. Meyer, F.K. 2001. Kritische Revision der "Thlaspi"-Arten Europas, Afrikas und Vorderasiens, Spezieller Teil, I. Thlaspi L. Haussknechtia, 8: 3-42.

31. Milan, P., Hayashi, A.H. \& Appezzato-da-glória, B. 2006. Comparative leaf morphology and anatomy of three Asteraceae species. Brazilian Archives of Biology and Technology, 49: 135-144.

32. Mummenhoff, K., Franzke, A. \& Koch, M. 1997a. Molecular phylogenetics of Thlaspi s.l. (Brassicaceae) based on chloroplast DNA restriction site variation and sequences of the internal transcribed spacers of nuclear ribosomal DNA. Canadian Journal of Botany, 75: 469-482.

33. Mummenhoff, K., Franzke, K.A. \& Koch, M. 1997b. Molecular data reveal convergence in fruit characters used in the classification of Thlaspi s.l. (Brassicaceae). Botanical Journal of the Linnean Society, 125: 183-199.

34. Mummenhoff, K. \& Koch, M. 1994. Chloroplast DNA restriction site variation and phylogenetic relationships in the genus Thlaspi sensu lato (Brassicaceae). Systematic Botany, 19: 73-88.

35. Orcan, N. \& Binzet, R. 2002. The Anatomical and Palynological Properties of Alyssum obtusifolium Steven ex DC. (Brassicaceae). Turkish Journal of Botany, 27: 63-68.

36. Ozcan, M., Demiralay, M. \& Kahriman, A. 2015. Leaf anatomical notes on Cirsium Miller (Asteraceae, Carduoideae) from Turkey. Plant Systematics and Evolution, 301: 1995-2012.

37. Selvi, S. \& Paksoy, M.Y. 2013. Comparative anatomy of stem and leaf of Ricotia L. growing in Turkey. Bangladesh Journal of Botany, 42: 123-133.

38. SPSS, 2006. SPSS Base 15.0 for windows. SPSS Inc., Chicago.

39. Stace, C.A. 1984. The Taxonomic Importance of the Leaf Surface. In: Heywood, V.H. \& Moore, D.M. (eds) Current concepts in plant taxonomy. Academic Press, London, 67$94 \mathrm{pp}$.

40. Wilkinson, H.P. 1979. The plant surface (mainly leaf). In: Metcalfe, C.R. \& Chalk, L. (eds) Anatomy of the dicotyledons, Vol. 1. Clarendon Press, Oxford, 97-167 pp.

41. Yentür, S. 2003. Bitki Anatomisi. Faculty of Science Publishing, İstanbul, 560 pp.

42. Yıldırıml, Ş. 2001. Thlaspi L. In: Güner, A., Özhatay, N., Ekim, T. \& Başer, K.H.C. (eds) Flora of Turkey and the East Aegean Islands 11. Edinburgh University Press, Edinburgh, 34-35 pp.

43. Zunk, K., Mummenhoff, K., Koch, M. \& Hurka, H. 1996. Phylogenetic relationships of Thlaspi s.l. (Subtribe Thlaspidinae, Lepidieae) and allied genera based on chloroplast DNA restriction-site variation. Theoretical and Applied Genetics, 92: 375-381. 